\title{
Apolipoprotein E genotypes and outcome from out of hospital cardiac arrest
}

\author{
W T Longstreth Jr, G D Schellenberg, C E Fahrenbruch, L A Cobb, M K Copass, D S Siscovick
}

J Neurol Neurosurg Psychiatry 2003;74:1441-1443

Genetic factors may influence outcome from cardiac arrest. In Seattle, WA, paramedics collected blood specimens from patients who had suffered cardiac arrest outside of a medical institution (out of hospital cardiac arrest). We examined associations between apolipoprotein $E$ (APOE) genotype and outcome in 134 who died "in the field", 131 who died in the hospital, 198 patients who were discharged from hospital alive, and 64 control subjects. APOE genotype was not significantly related to outcome, including being alive at and being independent by 3 months after the arrest. Specifically, having one or two alleles of $A P O E \in 4$ or having $A P O E \in 3 / \epsilon 3$ was not related to outcome, even after controlling for age, sex, race, and initial rhythm. We failed to confirm previous studies and found no significant associations between $A P O E$ genotype and outcome from out of hospital cardiac arrest.

W hether genetic factors influence outcome after cardiac arrest is uncertain. Three alleles of the apolipoprotein E gene ( $A P O E \in 2, \epsilon 3$, and $\epsilon 4)$ encode three isoforms of the protein (E2, E3, and E4), which exert differential effects on response of nervous tissue to injury. ${ }^{1}$ In a study of transgenic mice, $A P O E \in 4$ was associated with greater hippocampal damage after global cerebral ischaemia, ${ }^{2}$ contrary to results in 58 humans who died after surviving a mean of 5.7 days after cardiac arrest. ${ }^{3}$ In another study of 80 patients admitted after cardiac arrest, having the $A P O E \in 3 / € 3$ genotype was associated with a better survival and neurological outcome. ${ }^{4}$ If genetic factors affect outcome after cardiac arrest, they could provide clues about pathophysiology and could suggest novel treatments. We explored associations of outcome with APOE genotype using blood specimens collected by paramedics from patients they treated for out of hospital cardiac arrest.

\section{METHODS}

As part of another study, ${ }^{5}$ paramedics in Seattle have collected blood specimens from patients with out of hospital cardiac arrest since 1988. Regardless of the outcome of resuscitation, paramedics collect the specimens as soon as possible after return of spontaneous circulation or immediately upon cessation of resuscitative efforts. Blood was collected into tubes containing EDTA, and transported to the Clinical Nutrition Research Laboratory at Harborview Medical Center, where the white blood cells were separated and stored at $-70^{\circ} \mathrm{C}$.

$A P O E$ genotyping was attempted on all specimens collected from 1989 to 1995 from patients who had survived to hospital discharge. DNA was prepared from buffy coat preparations by a modification of a salting out procedure. ${ }^{6}$ The APOE genotypes were determined using previously described PCR conditions ${ }^{7}$ and HhaI restriction digest methods. ${ }^{8}$ For comparison, genotyping was also attempted on randomly selected specimens collected in the same time interval from an approximately equal number of patients who died in hospital; about one third this number of patients who died "in the field"; and about one third this number of community control subjects from the study described above. ${ }^{5}$ Genotyping was performed without knowledge of any clinical information, and was successful in $90.5 \%$ of patients: $80.8 \%$ for those who died in the field; $93.0 \%$ for those who died in hospital; $92.0 \%$ for those who survived to hospital discharge; and $87.7 \%$ for control subjects. We subsequently reclassified patients based on the most current and accurate information collected by personnel with the prehospital emergency medical system in Seattle (Medic One), as part of continuing efforts to improve the quality of care of these patients. We included those who died in the emergency department with those who died in the field. With this redistribution, APOE genotype was available on: 134 who died in the field, 131 who died in hospital, 198 patients who survived to be discharged from hospital, and 64 control subjects.

We also used this database to obtain information on patients' age, sex, race (white $v$ other), and initial rhythm (ventricular fibrillation $v$ other). For patients discharged from the hospital, personnel used medical records and telephone follow up to decide survival status at 3 months and recovery of independence at any time by 3 months after the cardiac arrest. Personnel collected all of the information without knowledge of the results of the genotyping.

Outcomes used in this study included: death in the field, death in hospital, survival to discharge from hospital, survival at 3 months, and independence by 3 months. To evaluate associations between these outcomes and genotype, we used logistic regression, with the outcome as the dependent variable and the genotype as the independent variable. In addition to unadjusted models, we also evaluated models adjusted for age, sex, race and initial rhythm. An association was considered significant if the $p$ value for the genotype coefficient in the logistic regression model was $<0.05$. Race was unknown in three patients. Survival status at 3 months was unknown for 19 patients. In these patients, the independence status at the last contact was used for the status by 3 months. No other variables had missing values, and the maximum number of missing values for any model was 20 patients, occurring in models where the dependent variable was survival at 3 months. Analyses were performed using SPSS statistical software (version 10.0 for Macintosh; SPSS Inc., Chicago, IL, USA). The Human Subjects Review Committee at the University of Washington approved the study.

\section{RESULTS}

Characteristics of the study groups are shown in table 1, and the results of the $A P O E$ genotyping in the four study groups are shown in table 2 . In the unadjusted and adjusted models, having one or two alleles of $A P O E \in 4$ was not significantly related to the outcomes examined: having a cardiac arrest $v$

Abbreviations: $\mathrm{APOE}$, apolipoprotein $\mathrm{E}$ 
Table 1 Characteristic of study groups

\begin{tabular}{lcclll}
\hline Characteristic* & $\begin{array}{l}\text { Death in field } \\
(\mathbf{n}=\mathbf{1 3 4 )}\end{array}$ & $\begin{array}{l}\text { Death in hospital } \\
(\mathbf{n}=131)\end{array}$ & $\begin{array}{l}\text { Survival to discharge } \\
(\mathbf{n}=198)\end{array}$ & $\begin{array}{l}\text { Control subjects } \\
(\mathbf{n}=64)\end{array}$ & $\begin{array}{l}\text { Total } \\
(\mathbf{n}=\mathbf{5 2 7})\end{array}$ \\
\hline Age mean (SD) & $66.6(16.7)$ & $65.5(15.6)$ & $63.5(15.4)$ & $58.0(10.2)$ & $64.1(15.4)$ \\
Men (\%) & $92(69)$ & $97(74)$ & $155(78)$ & $50(78)$ & $394(75)$ \\
White (\%) & $111(84)$ & $106(82)$ & $164(83)$ & $61(95)$ & $442(84)$ \\
VF (\%) & $46(34)$ & $71(54 \%)$ & $177(89)$ & - & - \\
\hline
\end{tabular}

*Values missing for race in three subjects. Otherwise no missing values.

VF, initial rhythm being ventricular fibrillation in those subjects who experienced a cardiac arrest.

Table 2 Apolipoprotein E genotypes and outcome from out of hospital cardiac arrest

\begin{tabular}{lllclr}
\hline APOE genotype & Death in field & Death in hospital & Survival to discharge & Control subjects & Total \\
\hline$\epsilon 2 / \epsilon 2$ & - & - & $1(00.5)$ & - & $1(00.2)$ \\
$\epsilon 2 / \epsilon 3$ & $15(11.2)$ & $11(08.4)$ & $15(07.6)$ & $-1(10.9)$ & $48(09.1)$ \\
$\epsilon 2 / \epsilon 4$ & $5(03.7)$ & $1(00.8)$ & - & - & $6(01.1)$ \\
$\epsilon 3 / \epsilon 3$ & $87(64.9)$ & $84(64.1)$ & $138(69.7)$ & $41(64.1)$ & $350(66.4)$ \\
$\epsilon 3 / \epsilon 4$ & $25(18.7)$ & $31(23.7)$ & $43(21.7)$ & $16(25.0)$ & $115(21.8)$ \\
$\epsilon 4 / \epsilon 4$ & $2(01.5)$ & $4(03.1)$ & $1(00.5)$ & - & $7(01.3)$ \\
Total & 134 & 131 & 198 & 64 & 527 \\
\hline
\end{tabular}

being a control $(24.2 \% \vee 25.0 \%$ respectively, having one or two alleles of $A P O E \in 4)$; for all cardiac arrest patients, being resuscitated and admitted $v$ not $(24.3 \% v 23.9 \%)$; and for patients admitted, surviving to discharge $v$ not $(22.2 \% v$ $27.5 \%)$; surviving to 3 months $v$ not $(21.6 \% v 27.0 \%)$; or being independent by 3 months $v$ not $(22.6 \% v 26.1 \%)$. Similarly, in the unadjusted and adjusted models, having the $A P O E \in 3 / \epsilon 3$ genotype was not significantly related to the outcomes examined: having a cardiac arrest $v$ being a control $(66.7 \%$ $v 64.1 \%$ respectively, having APOE $€ 3 / € 3$ genotype); for all cardiac arrest patients, being resuscitated and admitted $v$ not $(67.5 \% \vee 64.9 \%)$; and for patients admitted, surviving to discharge $v$ not $(69.7 \% v 64.1 \%)$; surviving to 3 months $v$ not $(70.4 \% \vee 65.5 \%)$; or being independent by 3 months $v$ not $(69.0 \% \vee 65.8 \%)$. Associations with genotypes for survival at and independence by 3 months remained insignificant when only those discharged from the hospital were considered.

\section{DISCUSSION}

How apolipoprotein E genotypes affect outcomes from brain injury is uncertain but seemingly dependent upon the mechanism of injury. ${ }^{1}$ Detrimental effects of having one or two alleles of $A P O E \in 4$ have been demonstrated for traumatic brain injury ${ }^{9}$ and haemorrhagic stroke ${ }^{10-12}$ but not for ischaemic stroke. ${ }^{11}{ }^{13}$ As expected, based on previous studies of hippocampal damage and neurological outcome in patients with cardiac arrest, ${ }^{3}{ }^{4}$ we found that having one or two alleles of $A P O E \in 4$ was not associated with outcome. In this regard, global and focal brain ischaemia are similar. Unlike a previous study, ${ }^{4}$ we found that $A P O E \in 3 / € 3$ genotype was also not significantly associated with any of the outcomes examined. Why the results from the two studies differ is unclear. We examined a larger number and a less select group of patients than in the previous study. Perhaps the results would have differed if we had succeeded in genotyping all the specimens, but the genotyping was performed without any clinical information, making such a bias unlikely. Perhaps more detailed determination of neurological outcome is needed to identify such associations. Even if an association with $A P O E$ genotype is lacking, it is likely that other genetic factors that affect the response to global brain ischaemia accompanying cardiac arrest exist. Understanding such genetic factors may hold the key to understanding brain protection and resuscitation.

\section{ACKNOWLEDGEMENTS}

The study was possible only because of the outstanding efforts of the firefighters and paramedics of the Seattle Fire Department. We also appreciate the dedicated work of staff of the Medic One Program in determining demographics and outcomes.

This study was supported by grants from the National Heart, Lung, and Blood Institute (HL41993 DSS), the National Institute of Aging (P50 AG05136, GDS), and the Medic One Foundation.

\section{Authors' affiliations}

W T Longstreth Jr, C E Fahrenbruch, L A Cobb, M K Copass,

D S Siscovick, Departments of Neurology, Epidemiology, and Medicine, Divisions of General Internal Medicine and Cardiology, University of Washington, USA

G D Schellenberg, Department of Medicine, Division of Gerontology and Geriatric Medicine (Schellenberg), Veterans Affairs Puget Sound Health Care System, Seattle Division, Seattle, WA, USA

Competing interest: none declared

Correspondence to: Dr W T Longstreth Jr, Department of Neurology, Box 359775, Harborview Medical Center, 325 Ninth Avenue, Seattle, WA 98104-2420, USA; wl@u.washington.edu

\section{REFERENCES}

1 Horsburgh K, McCarron MO, White F, et al. The role of apolipoprotein E in Alzheimer's disease, acute brain injury and cerebrovascular disease: evidence of common mechanisms and utility of animal models. Neurobiol Aging 2000;21:245-55.

2 Horsburgh K, McCulloch J, Nilsen M, et al. Increased neuronal damage and apoE immunoreactivity in human apolipoprotein E, E4 isoform-specific, transgenic mice after global cerebral ischaemia. Eur J Neurosci 2000;12:4309-17.

3 Horsburgh K, Graham DI, Stewart J, et al. Influence of apolipoprotein E genotype on neuronal damage and apoE immunoreactivity in human hippocampus following global ischemia. J Neuropathol Exp Neurol 1999;58:227-34

4 Schiefermeier M, Kollegger H, Madl C, et al. Apolipoprotein E polymorphism: survival and neurological outcome after cardiopulmonary resuscitation. Stroke 2000:31:2068-73.

5 Siscovick DS, Raghunathan TE, King I, et al. Dietary intake and cell membrane levels of long-chain $n-3$ polyunsaturated fatty acids and the risk of primary cardiac arrest. JAMA 1995;274:1363-7.

6 Miller SA, Dykes DD, Polesky HF. A simple salting out procedure for extracting DNA from human nucleated cells. Nucleic Acids Res 1988;16:1215.

7 Emi M, Wu LL, Robertson MA, et al. Genotyping and sequence analysis of apolipoprotein E isoforms. Genomics 1988;3:373-9.

8 Hixson JE, Vernier DT. Restriction isotyping of human apolipoprotein E by gene amplification and cleavage with Hhal. J Lipid Res 1990;31:545-8.

9 Teasdale GM, Nicoll JA, Murray G, et al. Association of apolipoprotein E polymorphism with outcome after head injury. Lancet 1997;350:1069-71. 
10 Alberts MJ, Graffagnino C, McClenny C, et al. ApoE genotype and survival from intracerebral haemorrhage. Lancet 1995;346:575.

11 McCarron MO, Muir KW, Weir CJ, et al. The apolipoprotein E epsilon4 allele and outcome in cerebrovascular disease. Stroke 1998:29:1882-7.
12 Leung $\mathrm{CH}$, Poon WS, Yu LM, et al. Apolipoprotein e genotype and outcome in aneurysmal subarachnoid hemorrhage. Stroke 2002;33:548-52.

13 McCarron MO, Muir KW, Nicoll JA, et al. Prospective study of apolipoprotein E genotype and functional outcome following ischemic stroke. Arch Neurol 2000;57:1480-4.

\section{HISTORICAL NOTE}

\section{Sir Thomas Clifford Allbutt}

T homas Clifford Allbutt, (b. 20 July 1836; d. 22 February 1925 ) is of interest to neurologists as the main instigator, along with Gowers, of the routine clinical use of the ophthalmoscope.

He was born in Dewsbury, Yorkshire, the only son of Reverend Thomas Allbutt and his wife Marianne, daughter of Robert Wooler. He was educated at St Peter's School, York, and Caius College, Cambridge, where he graduated in 1859 with first class honours in the natural sciences tripos. He trained at St George's Hospital, graduating MB in 1860. After training, Allbutt was appointed in 1864 to the staff of the General Infirmary at Leeds, and lectured on the practice of physic and anatomy at the Yorkshire College. Leeds remained his home for 28 years.

Allbutt was one of the first to employ the ophthalmoscope in Britain'; importantly, he extended its use beyond the diagnosis of ocular diseases. Like Gowers, he tried to use fundoscopy to show the numerous and important signs (optic atrophy, papilloedema and such) of intracranial disease that the ophthalmoscope could provide. He observed:

"The number of physicians who are working with the ophthalmoscope in England may, I believe, be counted upon the fingers of one hand. ${ }^{\prime \prime}$

In 1866, Allbutt invented the conveniently portable 6 inch clinical thermometer, able to record temperature in 5 minutes. It replaced a 12 inch standard model that required 20 minutes. ${ }^{2}$ Other studies also led to the improved treatment of arterial diseases when he proved that narrowing of the coronary arteries causes angina.

By 1889, Allbutt had acquired an unrivalled reputation in northern England, but curiously he retired from consulting practice to become a commissioner in lunacy. After 3 years in London, however, he was tempted to the Regius chair of Physic at Cambridge. Election as physician to Addenbrooke's Hospital followed in 1900; thereafter his work and reputation were more widely acclaimed. He established and edited the System of medicine, ${ }^{3}$ published in eight volumes between the years 1896 and 1899, to which he contributed 15 sections (volumes VI, VII, and VIII contain diseases of the nervous system, demonstrating his neurological predilections); a second edition, with which Sir Humphrey Davy Rolleston was associated, appeared in 11 volumes (1905-11). Along with Osler's textbook, it remained the finest comprehensive text on medicine for many years. A good scientist, one of his aphorisms was:

"The use of hypotheses lies not in the display of ingenuity, but in the labour of verification." 4

Allbutt was prominent in the Royal College of Physicians. ${ }^{5}$ He delivered the Goulstonian Lectures in 1884, the Harveian Oration in 1900, and the Fitzpatrick Lectures in 1909-10. He was awarded the Moxon Medal in 1921, and became a Censor. He was a founder member of the Medical Research Council, and in 1916 at the age of 80 was elected president of the British Medical Association-an office he held until 1921.

Allbutt was a man renowned for his industry, energy, and protean knowledge of medicine. However, he realised that the growth of knowledge made specialisation a necessity:
"It is obvious that the results of such advances prescribe for the clinical physician methods which cannot be pursued without expert assistance; a physician engaged in busy practice cannot himself undertake even the verifications required in the conduct of individual cases. Skill in modern laboratory work is as far out of the reach of the untaught as performance on a musical instrument. In spite, therefore, of the encyclopaedic tradition which has persisted from Aristotle through the Arab and medieval schools down to Herbert Spencer, it is forced upon us in our own day that in a pursuit so many sided as medicine, whether in its scientific or in its practical aspect, we have to submit more and more to that division of labour which has been a condition of advance in all other walks of life."

He received the KCB in 1907 and was made Privy Councillor in 1920.

The many honorary degrees bestowed upon him signify his distinction: Hon DSc Oxon, Manchester, Leeds, Hon LLD Glasgow, McGill, Toronto, St Andrew's, Durham, Hon MD Dublin.

Allbutt was a student and scholar in both classical and modern medical history. Among his writings was Greek medicine in Rome and other historical essays. ${ }^{7}$ His own writing was plain but stylish and he hated the careless or ungrammatical English ${ }^{8}$ of some other medical writers. He was described as sanguine and calm in demeanour, his bearing courtly and aristocratic. It is suggested that the author George Eliot's character Lydgate in Middlemarch was based on Allbutt, whom Eliot knew in her time in Yorkshire. ${ }^{9}$

He married Susan, daughter of Thomas England, a merchant from Headingley, Leeds, in 1869, but they had no children. ${ }^{10}$ He died in Cambridge. ${ }^{11}$

J M S Pearce 304 Beverley Road, Anlaby, Hull HU10 7BG, UK; jmspearce@freenet.co.uk

\section{References}

1 Allbutt TC. On the use of the ophthalmoscope in diseases of the nervous system and of the kidneys; also in certain other general disorders. London and New York: Macmillan, 1871.

2 Pearce JMS. Clinical thermometers. QJM 2002;95:1-2.

3 Allbutt TC, ed. A system of medicine by many writers. London: Macmillan, 1896-99.

4 Allbutt TC. In: Asher R, ed. A sense of Asher: a new miscellany. London: The Keynes Press, BMA, 1983

5 Royal College of Physicians of London. Munk's Roll vol IV (1826-1925). London: Royal College of Physicians of London, 1955:290-2. see www.rcplondon.ac.uk/scripts/munk_results_volume.asp?volume = IV

6 Allbutt TC. In: The Encyclopaedia Britannica. A dictionary of arts, sciences, literature and general information, 11 th edn. Cambridge: Cambridge University Press, $1911 ; 18: 66$.

7 Allbutt TC. Greek medicine in Rome and other historical essays. London: Macmillan, 1921.

8 Allbutt TC. Notes on the composition of scientific papers. London: Macmillan, 1904.

9 Eliot George. "To Thomas Clifford Allbutt." 1 Nov 1873. In: Haight GS, ed. Selections from George Eliot's Letters. New Haven and London: Yale University Press, 1985:427.

10 Oxford University Press. The Dictionary of National Biograph. London: Oxford University Press, 1930.

11 Rolleston HD. The Right Honourable Sir Thomas Clifford Allbutt. London: Macmillan, 1929 